\title{
TESSITURAS PÓS-MODERNAS EM RESPIRAÇÃO ARTIFICIAL, DE RICARDO PIGLIA E À MÃ̃ ESQUERDA, DE FAUSTO WOLFF
}

Postmodern tenses in artificial respiration, by Ricardo Piglia and left hand, by Fausto Wolff

\author{
Alexandre Leidens ${ }^{1}$
}

${ }^{1}$ Programa de Pós-Graduação em Letras -UTFPR - Pato Branco PR.

RESUMO: Observando as questões pós-modernas ligadas à literatura contemporânea, bem como o apelo comparatista, tão em voga na atualidade, este artigo busca subsidiar brevemente algumas particularidades da metaficção historiográfica e analisar aspectos da pós-modernidade sobre os corpus-escritos de duas obras em particular: Respiração Artificial, de Ricardo Piglia (2010) e À mão esquerda, de Fausto Wolff (2007). Das obras em questão pretende-se extrair pequenas características que são costumeiramente consideradas pós-modernas, como a rediscussão de aspectos históricos, fundamentais para a história recente dos dois países de onde as obras provêm: Argentina e Brasil; o multiperspectivismo, pela clara evidência de que se contrastam diferentes formas de enxergar determinado fato ou história; e a fragmentação, onde a inferência do leitor se torna mais necessária, que se somarão à metaficção historiográfica para constituir uma análise pós-moderna dos dois romances. Como constructo básico para essas reflexões, serão utilizados autores como Eco (2002) e Hutcheon (1991). Ademais, a análise se dará de forma qualitativa em abordagem bibliográfica, observando algumas dessas características nos romances e ressaltando sua importância para a constituição da obra literária. Palavras-chave: Pós-modernismo. Literatura Comparada. Metaficção Historiográfica.

ABSTRACT: Observing postmodern issues related to contemporary literature, as well as the comparative appeal, so popular today, this article seeks to subsidize the particularities of historiographic metafiction and aspects of 
postmodernity over the corpus of writings of two works: Artificial Respiration, by Ricardo Piglia (2010) and Left Hand, by Fausto Wolff (2007). Small characteristics, which are usually considered postmodern will be extracted from these works, such as the re-discussion of historical aspects, fundamental to the recent history of the two countries where the works come from: Argentina and Brazil; the multiperspectivism, by the clear evidence that different ways of seeing a certain fact or history are contrasted; and fragmentation, where the inference of the reader becomes more necessary, which will be added to the historiographic metafiction to constitute a postmodern analysis of the two novels. As a basic construct for these reflections, authors such as Eco (2002) and Hutcheon (1991) will be used. In addition, the analysis will be qualitative in a bibliographical approach, observing some of these characteristics in the novels and emphasizing their importance for the constitution of the literary work.

Keywords: Postmodernism. Comparative literature. Historiographic Metafiction.

\section{Introdução}

Muito em voga nas últimas décadas, a concepção pós-moderna na literatura tem sido abordada em um grande número de produções. Um dos pontos característicos, que fazem o pós-modernismo na literatura se tornar interessante é a multiplicidade de formas com que o movimento permite que sejam concepções tradicionais questionadas e, no mínimo, repensadas. De fato, o vértice questionador se destaca no pós-modernismo; entretanto, esse questionamento não é algo desprovido de criatividade e produção, pelo contrário, é um questionamento que proporciona o aparecimento e o desenvolvimento de obras literárias complexas, inovadoras tanto na forma quanto no conteúdo.

Desse pensamento, extraem-se algumas propriedades do pós-modernismo na literatura, pois, as obras tendem a apresentar peculiaridades, como a fragmentação, a intertextualidade, a rediscussão histórica e a metaficção historiográfica. No entanto, importa perceber também que as nuances pós-modernas não se mantêm em um plano formalista na concepção das obras, pois ultrapassam essa barreira, sendo não raro debatidas dentro das próprias obras, ancoradas em situações pelas quais os seus personagens estão passando. Situações essas, como preocupações, acontecimentos, questionamentos e reflexões essencialmente pós-modernas. Dois exemplos de obras dessa natureza são Respiração artificial, do argentino Ricardo Piglia e $\boldsymbol{A}$ mão esquerda, do brasileiro Fausto Wolff. Em ambas, há indiscutíveis características pós-modernas e a inclusão de seus personagens em dramas e conflitos que muito se assemelham às discussões pós-modernas sobre literatura e filosofia, bem como tratam de maneira singular uma possível rediscussão ou releitura do seu tempo, da sua geração, ficcionalizando personagens de relevância histórica e debatendo o próprio ato da escrita, cada uma à sua maneira.

Desse modo, este artigo se propõe a subsidiar de forma bastante sucinta algumas particularidades da metaficção historiográfica, além de analisar brevemente alguns aspectos da reflexão pós-moderna sobre a escrita em determinados momentos das obras selecionadas. A questão da rediscussão sobre aspectos 
históricos, bem como o multiperspectivismo e a fragmentação inseridas nos romances também serão observadas. Ademais, a análise se dará de forma qualitativa em abordagem bibliográfica, observando algumas dessas características nos romances e ressaltando sua importância para a constituição da obra literária.

\section{Pressupostos Pós-modernos}

O pós-modernismo apareceu como uma corrente estética entre os estudos teóricos da literatura, em concepções defendidas por não poucos pesquisadores que acreditam em uma mudança no panorama literário ocorrida sobretudo a partir da segunda metade do século XX. Emaranhado em contradições e buscando seguidamente referências em outras formas de arte, bem como na própria literatura e na história, o pós-modernismo é uma confluência e uma convergência bastante interessante de releitura e referências, sobretudo quando absorvidas na obra, inúmeras formas de enxergar os mesmos aspectos que, não raro, são contraditórias e destoantes em alguns pontos.

Um dos seus aspectos mais relevantes é a Metaficção historiográfica, assinalada por Hutcheon (1991). É justamente nessa perspectiva que se encontram as relações da literatura pós-moderna com a história. É consenso que não há uma concepção de história que seja única, abrangente e inquestionável. Tem-se a história como narrativa, de maneira que são dadas na literatura diferentes perspectivas à descrição dos fatos históricos que a permeiam. Embora predomine uma reflexão diversa e anedótica de eventos históricos, por um viés que desconstrói o aceito como verdade absoluta, a metaficção historiográfica enseja instigar o leitor a observá-la de diferentes maneiras, de tal forma que compreenda que o discurso histórico oficial ou tido como correto é insuficiente e incapaz de reprodução absoluta dos fatos, deixando margem à discussão sobre o que foi escrito e esquecido, sobre a quem foi dada voz e a quem foi delegado o silêncio e sobre qual face da história foi baseada a narrativa tida como oficial. A metaficção historiográfica não apenas relê o passado, mas o discute e abre as possibilidades de interpretação do leitor, com vistas à sua produção e recepção.

Pensadas anteriormente, literatura e história, como ramos de uma mesma atividade, hoje são observadas de maneira que suas definições e inter-relações sejam estabelecidas a partir do enfoque dado sob análise e, também, considerando o momento histórico em questão. A literatura pós-moderna se utiliza do conhecimento histórico problematizando-o e ficcionalizando-o. Para isso, não apenas se apropria desse, mas também o constrói sob outra perspectiva, um outro olhar, que geralmente evidencia as limitações de uma narrativa única, demonstrando uma intensa capacidade reflexiva e questionadora.
A metaficção historiográfica. [...] mantém a distinção de sua auto-representação for- mal e de seu contexto histórico, e ao fazê- -lo problematiza a própria possibilidade de conhecimento histórico, porque aí não existe conciliação, não existe dialética - apenas uma contradição irresoluta [...] (HUTCHEON, 1991, p. 142).

O romance pós-moderno é contraditório, problematiza e questiona a narrativa histórica e nela mantém sua base referencial para a ficcionalização. O que faz é repensar e recolocar alguns fatos históricos dentro da ficção, usando para isso importantes personagens de maior ou menor relevância. Considerando a complexidade que a inserção da metaficção historiográfica no romance adquire, não surpreende que ao leitor caiba uma atuação mais direta e construtiva do texto, determinando uma série de possibilidades que norteiam 
toda a forma de releitura e questionamento. O leitor inocente provavelmente encontrará uma série de dificuldades na metaficção historiográfica, visto que é necessário um mínimo de preparo para que consiga fazer as leituras e as ligações com as referências constantemente utilizadas nessa gama de obras. Quanto mais capacitado for o leitor, mais rica será sua leitura do romance pós-moderno. Nesse meio, utilizando-se das várias alternativas que a construção estética pós-moderna apresenta, fazendo com que as obras literárias fiquem cada vez mais multifacetadas, mais elaboradas e de leitura mais trabalhosa, quanto mais complexo for o romance, maior terá que ser a sua capacidade leitora. O escritor é quem projeta o leitor, é quem determina, de certa forma, ainda que não tenha controle sobre isso, a experiência de transformação pela qual o leitor passará (ECO, 2002) e qual o esforço necessário para que isso aconteça. Além disso, a inserção, na obra, de comentários ou reflexões sobre o próprio ato da escrita é também bastante utilizada nos romances pós-modernos. É provável a afirmação de que tanto a projeção do leitor, quanto a reflexão sobre o ato da escrita são maneiras de subverter o tradicional meio de escrever romances. No entanto, dentro dessa perspectiva, não há apenas essas características; essa forma estética

[...] faz parte da postura pós-modernista de confrontar os paradoxos da representação fictícia/histórica, do particular/geral e do presente/passado. E, por si só, essa confrontação é contraditória, pois se recusa a recuperar ou desintegrar qualquer um dos lados da dicotomia, e mesmo assim está mais do que disposta a explorar os dois (HUTCHEON, 1991, p. 142).

A questão da problematização do pós-modernismo se baseia não na particularização dos hemisférios do fictício/histórico, do particular/geral e do presente/passado, mas na sua representação de diferentes formas, seja unindo-os, seja separando-os, seja representando-os de forma fragmentária e desestabilizadora. A dicotomia diluída em manifestações do oposto, no pós-moderno é elevada e evidenciada de modo a dar voz e vez aos dois ângulos, sem negar o outro, revelando-os e explorando-os.

Nesse campo de atuação, muitos questionamentos são levantados em primeira instância por concepções que acreditam que a literatura em algumas de suas facetas deturpa a visão histórica e apresenta concepções não verdadeiras, ficcionalizadas, que fazem mais a suscitar a dúvida relativa àqueles determinados fatos do que a criar um romance histórico. À literatura não cabe essa preocupação com o discurso de veracidade histórica, pois é "um discurso que, precisamente, não pode ser submetido ao teste da verdade; ela não é verdadeira nem falsa, e não faz sentido levantar essa questão: é isso que define seu próprio status de 'ficção'." (TODOROV, 1981, apud HUTCHEON, 1991, p. 146).

Entretanto, a ficção pós-moderna apresenta outro contingente de pensamento e releitura histórica. Hoje, observa-se que história e ficção não fazem mais parte da mesma ordem do discurso como acontecia anteriormente, sobretudo na falta de documentos históricos, em que a ficção servia também para pesquisas e comprovações das mais variadas ordens históricas. A ficcionalização tem o papel de sugestão e reescritura do passado, apresentando-o ao presente sem a obrigação de gerar conclusões definitivas, indicando, também, que historiadores e romancistas têm seus sujeitos como objetos de representação narrativa (HUTCHEON, 1991). Ademais, o romance pós-moderno na metaficção historiográfica não apenas ficcionaliza o conteúdo histórico, mas também subverte a sua constituição tradicional, faz isso por meio de estruturas metalinguísticas e jogos linguísticos, com estratégias narrativas 
diversas, utilizando a intertextualidade de forma aguda e eficaz, com narradores fragmentários e desestabilizados, que instauram a dúvida para o leitor não apenas sobre o conteúdo narrado, mas também sobre quem está narrando e de que forma o está fazendo, em uma desconstrução que valoriza, mais do que nunca, o não explicitado no texto, o não-dito, suas aberturas e leituras multiformes. De fato, a metaficção historiográfica se distingue por ser um meio de discussão e rediscussão, de debate aberto e ficcionalização constante sobre o bem que mais distingue e caracteriza o ser humano: a história. Para isso, se utiliza de uma subversão estrutural que só tende a deixar o romance mais complexo e elaborado.

\section{Respiração Artificial e À mão esquerda: a outra face da história em tessituras pós-modernas}

Ricardo Piglia é um dos maiores expoentes do pós-modernismo na América Latina e um dos mais expressivos autores argentinos das últimas décadas. Sua produção literária tem uma grande aceitação crítica e o faz ser equiparado aos seus antecessores Borges e Cortázar, sobretudo quando citado o romance Respiração artificial, lançado na década de 1980 e tido como uma obra prima do autor. Fausto Wolff é um conhecido jornalista brasileiro que detém uma vasta obra literária, da qual se destaca $\grave{A}$ mão esquerda, um dos mais complexos romances de sua geração, onde, em uma elaboração portentosa de seu tempo, figuram inúmeros atributos pós-modernos.

Em Respiração artificial, Piglia constrói um romance fragmentário, que em um primeiro momento é epistolar, dividido em duas partes, ambientado em meio à ditadura argentina, de início em 1976. Há, no romance, um alter ego do autor, por assim dizer, no personagem Emilio Renzi. Por ocasião do lançamento de seu primeiro livro, Renzi recebe uma carta de Marcelo Maggi, seu tio, irmão de sua mãe, que estava até então desaparecido. Seu conhecimento e sua curiosidade sobre o caso acabaram propulsionando a sua criação literária, entretanto, a única versão dos fatos que conhecia era a que circulava em seu meio familiar, sempre de forma comedida e não transparente. Maggi era tido como um transgressor na sua família, pois fugira de casa seis meses após seu casamento, aparentemente com uma dançarina de cabaré e com dinheiro roubado de sua mulher. Uma história peculiar, de interesse de Renzi, pois, a julgo do próprio narrador, "Não houve nenhuma outra tragédia na história de minha família; nenhum outro herói digno de ser lembrado. Várias versões circulavam secretamente, confusas, conjecturais." (PIGLIA, 2010, p. 10). A desaparição e o roubo se tornaram públicos, havendo, inclusive, alguns recortes de jornais que relatavam o caso escondidos na casa de Renzi. Seu tio é um enigma, pois, ainda que preso durante anos, sem sequer se defender, decide não retornar à família e manter-se isolado. Renzi tenta descobrir e o leitor também o faz, na medida em que avança na leitura, quem, de fato, é Marcelo Maggi; entretanto, no decorrer da obra, nem Renzi nem o leitor conseguem chegar a um consenso e Maggi continuará distante e reservado.

Tendo em vista a complexidade do romance frente ao espaço aqui disposto, foi necessário realizar um recorte para uma análise mais contundente e pontual de alguns aspectos do pós-modernismo no romance de Piglia. Dessa maneira, o trabalho analítico aqui será mantido apenas em alguns aspectos da breve introdução e na primeira carta de Maggi a Renzi. Além disso, poderão existir algumas citações ou ligações com outros pontos da obra; no entanto, serão apenas no sentido de complementar um contingente textual já analisado, sem haver um esforço interpretativo ou uma migração do corpus de análise para tal local. 
Intitulado "A prolixidade do real", o livro de Renzi é inspirado nessa tragédia familiar e o que gera o primeiro contato com o seu tio. Nas primeiras páginas da obra, Renzi faz uma breve introdução sobre a história de sua família e, aparentemente, justifica o seu interesse e o seu trabalho na construção de um romance a partir de tais fatos. Após o lançamento do livro, recebe a carta, na qual se percebe um senso crítico aguçado e um conhecimento de literatura.

Primeiras retificações, aulas práticas (dizia a carta). Ninguém jamais fez boa literatura com histórias de família. Regra de ouro para os escritores debutantes: quando a imaginação fraqueja, é preciso ser fiel aos detalhes. Os detalhes: a safada da minha primeira mulher, boquinha franzida, veias visíveis por baixo da pele translúcida. Péssimo sinal: pele transparente, mulher enganadora, só me dei conta tarde demais. Outra coisa: quem lhes falou de minha viagem à Colômbia? (PIGLIA, 2010, p. 13).

Como se nota, o primeiro impulso da carta é uma crítica ao romance lançado por Renzi, algo natural, uma vez que Maggi é pare ele uma inspiração dúbia. Ao mesmo tempo em que é seu agente propulsor, não influencia, verdadeiramente, na narrativa, pois as versões sobre seu desaparecimento descritas na obra são baseadas no ponto de vista de outrem. Deveras, o leitor não tem acesso ao livro lançado por Renzi, todo o conteúdo é sugerido durante as cartas, a partir de algumas citações e indicações que acabam, Renzi e Maggi, debatendo. Ainda nesse pequeno excerto, é perceptível a repulsa designada à ex-mulher, uma visão diferente da apresentada anteriormente por Renzi; a aparente falta de interesse de Maggi pela família e a sua surpresa sobre o fato de saberem de sua viagem à Colômbia. Visto que a "metaficção historiográfica se aproveita das verdades e das mentiras do registro histórico" (HUTCHEON, 1991, p. 152), seria possível afirmar que, de certo modo, o que Renzi fez com a história do tio foi metaficcionalizá-la e, em contato com essa produção, Maggi alerta-o sobre a problematização da referência. A obra dialoga diretamente com alguns pressupostos do pós-modernismo e não apenas isso, se estrutura justamente em cima desses alicerces pós-modernos, discutindo-os, mesmo sem que o leitor consiga perceber essas nuances que, todavia, estão ali encadeados, refletindo e rediscutindo questões puramente pós-modernas.

Na primeira carta aparecem alguns indícios de disputa política, que desenham um engajamento de Maggi em questões dessa natureza, ligados diretamente ao seu tempo, e apresentando uma visão de quem viveu uma época complicada, de evidente turbulência nesse meio.

Se estive preso e se saí nos jornais é porque sou radical, homem de don Amadeo Sabattini, e naquela época queriam dar um jeito em nós todos porque estavam chegando as eleições de 1943, que mais tarde resultariam no golpe de Rawson (tampouco lhe contaram essa história?) (PIGLIA, 2010, p. 14).

O desdém com que trata a falta de informação da família ou as distorções que tomaram as explicações sobre seu desaparecimento retratam uma revisão sobre os fatos, de maneira que a família pudesse criar uma narrativa e contá-la da forma com que quisesse. No trecho também há uma alusão ao golpe de Rawson, às eleições de 1943, eventos realmente ocorridos na Argentina e decisivos para as etapas posteriores nos rumos que o país tomaria. Ademais, Maggi se declara radical, seguidor de Amadeo Sabattini, importante político da época, com concepções claras sobre questões político-sociais. Prefigura-se, assim, um personagem com estigma de intelectual, politicamente atuante e enigmático. 
Maggi aparenta estar preocupado, nessa primeira carta, em desconstruir algumas ideias arraigadas à família e, consequentemente, ao imaginário de Renzi, muitas vezes, apenas sugerindo, possivelmente pelo seu conhecimento do temperamento familiar, as omissões e a maneira como foram narrados alguns acontecimentos. Claro exemplo é a visita que Coca, a dançarina com quem fugiu, fez à família e as reações destes frente à surpresa. Maggi supõe que Renzi não tem conhecimento de alguns fatos ou não suspeita do quesito moralmente condicionado sobre o que sabe a partir do juízo familiar. Dessa forma, o tio apresenta uma outra face da história: "Devolvi o dinheiro e os juros: é verdade que Coca foi à casa de vocês e que sua mãe quase teve uma síncope. Ninguém conta que ela disse: Vá se foder, na primeira vez que Esperancita a chamou de minha filha, e que tiveram que dar-lhe sais." (PIGLIA, 2010, p. 14). Ainda que esteja distante há muito tempo, Maggi está tão imerso no universo particular da família, que consegue ter noção exata sobre as reações que tiveram não apenas no evento da visita de Coca, como também com as possíveis histórias sobre ele contadas e inventadas no seio familiar. De certa forma, o que não apenas a relação entre os personagens Renzi e Maggi, mas toda a trama da história até esse momento faz é evidenciar que "O pós-modernismo estabelece, diferencia e depois dispersa as vozes (e os corpos) narrativas estáveis que utilizam a memória para tentar dar sentido ao passado." (HUTCHEON, 1991, p. 156). As pressuposições pós-modernas são engajadas de forma bastante convincente ao contexto da obra, à trama, à história e à descrição dos conflitos narrados até aqui e presumivelmente em tentativa de resolução ou de rediscussão a partir da carta.

A primeira carta, todavia, toma outro patamar a partir do momento em que Maggi começa a relatar o seu cotidiano atualmente, citando seu trabalho como professor de história no Colégio Nacional e sua amizade com um polonês bastante inteligente e destro no xadrez, que se diz discípulo de Wittgenstein. Esse polonês terá mais aparições no romance, tomará o lugar de Maggi em uma conversa longa, filosófica e politicamente profunda com Renzi, quando esse faz uma inútil viagem, no afã de encontrar o tio. Ao citar o amigo, Maggi o faz de maneira a sugerir que jogasse xadrez com James Joyce em Zurique e com o príncipe Alekhine, fazendo clara alusão ao comportamento desses dois personagens históricos, tendo em Joyce uma referência que se repetirá posteriormente na obra. Visto que uma das características pós-modernas que são bastante evidentes nos romances são as reuniões de citações e referências, podendo ser elas divergentes ou não, chama atenção o fato de Maggi, ao contar sobre o polonês (que depois se descobrirá chamar-se Tardewski), evidenciar que

Seu sonho é escrever um livro inteiramen-
te composto de citações. Seu romance não
é muito diferente disso, escrito a partir
dos relatos familiares; às vezes tenho a
sensação de estar ouvindo a voz de sua
mãe; o fato de você ter sabido disfarçá-la
com aquele estilo enfático não deixa de
ser, também, uma prova de delicadeza
(PIGLIA, 2010, p. 15).

Maggi aponta para o sonho do amigo e compara-o ao realizado por Renzi, por se tratar de um relato familiar, que é naturalmente multifacetado, de maneira que existam várias leituras de um mesmo fato, seguindo a perspectiva de cada um dos envolvidos. Essas características, a da contradição de relatos e a do multiperspectivismo são bastante importantes e latentes da literatura pós-moderna, como já explicitado de forma breve anteriormente. Mesmo disfarçando a voz da mãe, Renzi faz com que o tio se sinta parte da história, porém, com um ponto de 
vista diferente e contraditório. Maggi, assim, questiona alguns aspectos de "A prolixidade do real" e faz com que o leitor se pergunte sobre as verdades dos fatos, sobre qual será o desfecho da história e sobre em que pontos Renzi teria errado ao descrevê-los no livro. Entretanto, com o decorrer do romance, o leitor percebe que os fatos estão à disposição da narrativa, tanto a família quanto Maggi podem estar inventando evidências sobre acontecimentos que envolveram os dois e, nesse sentido, não cabe ao leitor querer fazer um julgamento entre a verdade e a mentira. Além disso, a questão do multiperspectivismo vista já na primeira carta é constante durante todo o romance, pois se trata de uma obra epistolar, normalmente aberta para a pluralidade de discursos e pontos de vista.

Maggi mantém sua obscuridade na carta, pois não remete sequer seu endereço para o sobrinho e dá margem à questão da transitoriedade: "Por enquanto, você pode me escrever para o clube social, Concordia, Entre Ríos." (PIGLIA, 2010, p. 15). Um homem que não se encontra, embora se tenha algumas referências como a província ou a cidade, e que pouco deixa que saibam sobre seu obtuso e aparentemente recatado cotidiano é um homem transitório, um ser humano que não faz parte de lugar algum e de tradição ou referência múltipla e que também não faz questão de estar ligado diretamente a algum lugar ou a alguma coisa. Essa capacidade transitória, essa enraização desconstruída é, também, particularmente pós-moderna. Para terminar a primeira carta que envia ao sobrinho, Maggi faz uso de uma observação, "P.S.: Claro que temos de conversar. Há outras versões que você precisa conhecer. Espero que venha me visitar. Quase já não me mexo, engordei demais. A história é o único lugar onde consigo descansar desse pesadelo de que tento acordar." (PIGLIA, 2010, p. 15).

Marcelo Maggi poderia ser, nesse excerto, a própria caracterização da multiplicidade de discursos e da pluralização das perspectivas, a capacitação da representação de várias vozes, que se consubstanciam em diferentes versões sobre os mesmos fatos, reapresentando-os e rediscutindo-os, fazendo com que o próprio Renzi repense os seus conceitos e interpretações, relatando uma revisão conceitual sobre seus escritos, ainda que isso apareça já no contexto introdutório, antes mesmo da apresentação da primeira carta, fato que demonstra a desestruturação temporal na ordem de exposição da trama. Renzi passa a questionar seus próprios escritos, "Ainda se encontram alguns exemplares do romance nas bancas de saldos das livrarias da Corrientes, e hoje a única coisa de que gosto no livro é o título (A prolixidade do real) e o efeito que ele produziu no homem a quem, sem querer, era dedicado." (PIGLIA, 2010, p. 13).

As características pós-modernas aqui elencadas que aparecem brevemente na primeira carta de Marcelo Maggi a Renzi ainda figuram no restante da narrativa, variando quanto ao momento e à forma e, além disso, a elas se unem algumas outras peculiaridades pós-modernas, como a referenciação mais clara à história da Argentina, à ditadura, à discussão sobre alguns grandes pensadores, filósofos e escritores contemporâneos de Piglia e Renzi ou anteriores, entre outras.

Em À mão esquerda, Fausto Wolff elabora um romance bastante complexo, com um teor multiperspectivo e polifônico acentuado. Nessa obra, tanto quanto em Respiração artificial, também há um alter-ego do autor no personagem Percival von Traurigzeit, com características semelhantes, como a profissão, a origem, as concepções políticas, o exílio, entre outras. Em um romance de quase quinhentas páginas, Fausto Wolff perpassa pela história de sua família desde o século XVI até o final da década de 90 . Essa grande saga familiar tem em Percival o seu personagem principal, de maneira que é ele 
ou sobre ele que se narram os acontecimentos; no entanto, há inúmeras transgressões e comentários sobre as décadas anteriores com foco em seus antepassados, além de leituras e reflexões sobre o seu tempo. À mão esquerda faz, além disso, um apanhado histórico, principalmente voltado para o período da ditadura militar no Brasil, desenhando de modo característico a sua geração, em meio aos problemas causados pelas suas opiniões políticas.

O romance de Wolff é composto por uma subversão estrutural, cada capítulo é narrado por um personagem em um dado momento histórico, de forma que os seus títulos são apenas o nome do personagem e o ano em que estão narrando aqueles fatos. Não há uma ordem cronológica na sua disposição, dessa forma, cabe ao leitor montar o "quebra-cabeça" do romance. Visto que há vários narradores, a maneira com que o fazem também difere de um para o outro e, por vezes, abordam um determinado fato em visões opostas. Nesse sentido, há uma simetria com a perspectiva observada anteriormente em Respiração artificial. Os dois romances dão uma clarividência aos movimentos de pensamento diversos dentro de uma mesma família, em construções que, embora partam de um mesmo fato, se transfiguram de maneiras ambíguas, alicerçando narrativas em sentidos opostos.

Essa confrontação que existe em alguns momentos no romance acontece sobretudo em discussões metalinguísticas com o narrador. Esse narrador é quem entrelaça e relê vários pontos da obra, não dando margem a um condicionamento à visão de Percival, de maneira que os dois narram dez capítulos. Mais uma vez, para este trabalho, foi preciso realizar um recorte para discussão, considerando a grandeza do romance, tanto no quesito físico quanto literário, bem como o espaço disposto em uma singela análise como a que se propõe este artigo, foram seleciona- dos alguns aspectos relacionados justamente à figura do narrador e sua lucidez dentro do romance. Não obstante, outros pontos serão abordados de forma breve sempre que necessário, ou citados indiretamente, sem que seja possível uma análise mais específica.

O narrador, já no começo do romance, trata de se apresentar e evidenciar o movimento de construção da narrativa no ato da escrita e, além disso, na reelaboração do condicionamento interpretativo da obra, dando alguns indícios de uma visão, até certo ponto, alheia, centrada e sistêmica tanto da obra quanto do ato da escrita.

Como o rumor de alguns dramas históricos de Shakespeare, como o coringa de certas peças de Brecht ou o diretor de cena de Nossa Cidade, de Thornton Wilder, sou o narrador. Sou produto da falta de talento do autor que não sabe colocar na boca de seus personagens camponeses, histórias de reis, príncipes e duques mortos na memória dos seus descendentes. Entrarei nesta história sempre que algum acontecimento - fato ou ficção - tiver de ser narrado imparcialmente, insensível a risos ou lágrimas (WOLFF, 2007, p. 26).

Nesse trecho é possível identificar a sensatez do narrador frente aos fatos narrados e, além disso, uma autoconsciência e um ponto de vista alheio, que problematiza e enfrenta as versões do narrado por outros personagens de forma imparcial. Mais do que isso, o narrador submete a obra a um outro constructo que tenta elaborar a narração dos fatos de forma vária, de tal maneira que ressalte que não há uma versão única dos fatos, tampouco uma versão que seja suficiente. O narrador é a voz da lucidez pós-moderna frente à metanarrativa, que, nesse caso, é naturalmente diversa, por se tratar do seio familiar do autor-personagem principal.

A discussão do ato da escrita revela um narrador que argumenta contra o próprio 
autor da obra, de forma relativamente cômica, que se relaciona também ao já proposto anteriormente.

- Fodam-se os leitores.

- Outra mentira. Você sabe que tem que escrever um romance direito, com princípio, meio e fim. Você já se embananou o suficiente com este negócio de botar muita gente contando a mesma história. Este troço é complicado, pois, se as versões dos demais personagens não conflitarem com a tua versão, todo mundo vai entender o farsante que você é (WOLFF, 2007, p. 248).

Nesse pequeno excerto é possível ver uma das preocupações das próprias concepções pós-modernas, ao estar, o narrador, discutindo com o autor da obra sobre os conflitos gerados pelo multiperspectivismo. Além disso, a metalinguagem está evidente, tanto quanto a reflexão sobre o ato da escrita, expondo ao leitor não apenas o texto pronto, mas também os percalços por que passa o autor no movimento de construção da obra. $\mathrm{O}$ leitor passa a ter uma visão mais ampla, que, nesse caso, se observa a partir da pluralidade de perspectivas e leituras dos mesmos fatos; a partir da observação de uma discussão entre narrador e autor que demonstra uma preocupação quanto à estética e a organização narrativa da obra; e a partir do ato criador por parte do autor. Este recurso historiciza a escrita da narrativa e apresenta o trabalho de construção da história (SOUZA, 2010). A leitura, de fato, será muito mais ampla, a partir dessas discussões, embora muitas vezes cômicas, entre narrador e autor.

Pérsio não está nada bem. Sua calma é doentia. Mais não posso dizer, caso contrário ele me expulsa do livro. Pois me meti a criticar minimamente a construção da história, e foi o que bastou para ele me deixar no banco por nove capítulos! Melhor falar de amenidades, portanto (WOLFF, 2010, p. 464-465).
Este é o início do último capítulo da obra, que também é atribuído ao narrador e da mesma forma deixa clara algumas observações metalinguísticas. Uma vez que o narrador é quem dá voz à razão no contexto da obra, não impressiona que ressalte a situação de Percival e requeira seu lugar na narrativa. Se não está bem, naturalmente não lhe será apetecível ter contato com a razão tão frequentemente. A metalinguagem não é a única característica constante nas inserções do narrador na obra.

\section{FANTE: 610,85}

Não comecem a implicar com a data deste capítulo. Quem é do ramo, sabe que Gogol usou este expediente para demonstrar ao leitor que o seu ele-personagem estava ficando maluco. O número que está no lugar do ano aí em cima é a prestação que a mulher do autor terá que pagar mensalmente por um novo carro que pretende comprar, e o Fante sou eu, o velho narrador, que me rebelei com a não definição do meu caráter. Como ontem estivemos relendo rapidamente algumas páginas de Ask the Dust, do John Fante, um autor de que ambos gostamos porque consegue transmitir suas pequenas alegrias e sofrimentos de modo a fazer com que acreditemos, sugeri que me batizasse de Fante a fim de que a cada dois, três capítulos o leitor não tivesse que se defrontar com a palavra Narrador que faz eu me sentir tão clean como um banheiro de senhoras em restaurante de luxo (WOLFF, 2007, p. 245).

Percebe-se no trecho acima que o narrador, por si só, faz algumas inserções intertextuais, citando por variadas vezes, autores clássicos, conhecidos ou esquecidos da literatura, da música, do teatro, entre outros. Essa inserção está presente não apenas nos capítulos destinados ao narrador e se entrelaça com a discussão metalinguística e a reflexão sobre o ato da escrita, também 
aparece seguidamente com outros narradores da família e principalmente com as colocações de Percival.

Nas duas obras aqui brevemente analisadas existem inúmeros diálogos com as concepções pós-modernas; entretanto, tentou-se ressaltar a rediscussão histórica no vértice familiar, com vistas ao multiperspectivismo e à pluralidade de leituras de um mesmo fato. Dentre os recortes realizados, isso fica bastante evidente na obra de Piglia, muito embora haja, ainda, uma grande gama de discussões e possibilidades, visto que se observou apenas a introdução da obra e a primeira carta de Maggi a Renzi. Perspectivas múltiplas podem aparecer, conforme se avança na leitura; porém, para uma análise focalizada apenas nos pontos acima mencionados, com subsídio teórico provindo sobretudo de Hutcheon (1991), crê-se que fazer um recorte na obra foi necessário, de maneira a conseguir atingir os objetivos iniciais sem abrir muitos parênteses ou outras possibilidades de reflexão em um mesmo trabalho. No entanto, mesmo recolhendo às análises apenas à introdução e a uma carta de poucas páginas, apresentou-se um campo muito profícuo para a experimentação e análise sob um vértice pós-moderno, tanto nas características do enredo, como nas peculiaridades dos personagens e nas situações com as quais são obrigados a lidar. De fato, trabalhou-se com variados momentos onde ficam visíveis as questões do multiperspectivismo e da pluralidade de leituras, o que demonstra, além disso, a qualidade da obra em questão.

No caso de Wolff, houve um recorte no romance para evidenciar sobretudo a questão da metalinguagem dentro da obra, tendo em vista, também, algumas discussões sobre a pluralidade de leituras a partir de um determinado fato, na forma de debate entre narrador e autor. Wolff também proporciona várias reflexões nessas mesmas perspectivas com apenas alguns capítulos, onde se torna perceptível o aparato pós-moderno na constituição do romance. Se na obra de Piglia, o multiperspectivismo se dá na busca de um personagem sobre a vida de outro, onde as versões dos fatos se contradizem e o fazem refletir constantemente com base nessas incongruências, na obra de Wolff, o multiperspectivismo fica evidente não só na narrativa, mas também na estrutura da obra, dando voz ao narrador como um personagem em que as ponderações e reflexões sobre a trama despertam no leitor uma observação mais distante e avaliativa, frente ao romance. A peculiaridade, nos dois casos, é justamente o debate aberto sobre diferentes possibilidades de interpretação de fatos semelhantes já dentro do contexto da obra, envolvendo seus personagens, sendo, nos excertos analisados, esses os seus maiores conflitos. De fato, Piglia e Wolff são dois dos maiores escritores contemporâneos na América Latina, com obras importantes nos seus contextos, que suscitam ainda muita discussão no meio literário, sob as mais variadas vertentes.

\section{Conclusão}

Ambos os escritores aqui analisados são reconhecidos pela qualidade literária que apresentam em suas obras e pela importância que elas adquiriram em um contexto que focaliza a observação e a reflexão frente a sua geração. Tanto em Respiração artificial, quanto em $\dot{A}$ mão esquerda há uma tênue linha entre o alter-ego dos seus escritores e os protagonistas de suas obras, envoltos em inúmeras questões importantes para sua geração que, nos dois casos, estão, de uma forma ou outra, ligadas à ditadura e à reflexão frente aos percalços decorridos pelo sistema político em vigor. O pós-modernismo, pelo menos sob o contingente aqui brevemente analisado, aparece em condições bastante peculiares, pois ultrapassa a questão da 
discussão teórica sobre os vértices de sua fundamentação e repensa algumas questões pós-modernas como situações conflitos dentro da própria trama dos romances, fato até certo ponto comum dentro da perspectiva pós-moderna e que sugere uma gama enorme de reflexões e multiplica as possibilidades de leitura da obra.

Ainda que se tenha realizado um grande recorte nas duas obras para análise, crê-se que foi possível observar alguns dos entraves, bastante pós-modernos, sobre os quais estão os personagens envoltos e, além disso, reconhecer essa perspectiva dentro da fundamentação da metaficção historiográfica. A estética pós-moderna permite que a literatura ultrapasse barreiras e explicite suas mais diferentes faces, fazendo com que não apenas o leitor seja mais ativo, mas também seja posto frente as mais variadas possibilidades apresentadas pela obras, quer em forma de releitura do passado ou em subversão estrutural, quer na fragmentação ou no multiperspectivismo, entre outras. Estudar o pós-modernismo é observar o tempo atual, é analisar de forma profícua as inúmeras possibilidades atraídas pelo romance ao leitor, é analisar os pilares das configurações do real na atualidade, é perceber que nenhuma verdade é absoluta e se encorajar a duvidar, a buscar versões diferentes e narrativas mais minimalistas ou mais abrangentes, ou ainda contraditórias. A estética pós-moderna é tão abrangente quanto são os dias atuais, é tão complexa quanto são as relações atuais e tão fragmentária quanto é a realidade atual. $\mathrm{O}$ pós-modernismo, embora não descarte nem menospreze as outras perspectivas estéticas, é um retrato do ser humano hodierno, das suas relações e das suas possibilidades, das suas leituras e da sua criatividade.

\section{REFERÊNCIAS}

ECO, U. Lector in fabula: a cooperação interpretativa no texto narrativo. Tradução de Attilio Cancian, São Paulo, Perspectiva, 2002.

HUTCHEON, L. Poética do pós-modernismo: história, teoria, ficção. Tradução de Ricardo Cruz. Rio de Janeiro: Imago Ed, 1991.

PIGLIA, R. Respiração artificial. Tradução de Heloisa Jahn. São Paulo: Companhia das Letras, 2010.

SOUZA, P. A. Autobiografia, história e memória em À mão esquerda de Fausto Wolff. 2010. 128f. Dissertação (Mestrado em Literatura Brasileira - Teoria da literatura) - Universidade Federal Fluminense, Niterói, 2010.

WOLFF, F. À mão esquerda. Belo Horizonte: Editora Leitura, 2007. 